\title{
Does Dietary Treatment Cause Obesity in Phenylketonuria? Comparison of Obesity Ratios of Patients Receiving Dietary Treatment and Tetrahydrobiopterin Treatment
}

\begin{tabular}{|c|c|c|}
\hline Author (s) & \multicolumn{2}{|c|}{ (D)Banu Kadıoğlu Yılmaz, (D) Fatih Kardaş, (D) Mustafa Kendirci } \\
\hline $\begin{array}{c}\text { Affiliation } \\
\text { (s) }\end{array}$ & Department of Pediatric Nutritic & , Erciyes University, Kayseri, Turkey \\
\hline $\begin{array}{c}\text { Article } \\
\text { Information }\end{array}$ & $\begin{array}{l}\text { Article Type: Original Articles } \\
\text { Article Group: Pediatric Metabolism }\end{array}$ & $\begin{array}{l}\text { Received: } 19.01 .2021 \\
\text { Accepted: } 23.03 .2021 \\
\text { Available Online: } 29.08 .2021\end{array}$ \\
\hline
\end{tabular}

Cite this article as: Kadıoğlu Yılmaz B, Kardaş F, Kendirci M. Does Dietary Treatment Cause Obesity in

Phenylketonuria? Comparison of Obesity Ratios of Patients Receiving Dietary Treatment and Tetrahydrobiopterin

Treatment. J Pediatr Acad 2021; 2: 59-63.

\section{Abstract}

Phenylketonuria is treated either with tetrahydrobiopterin $(\mathrm{BH} 4)$ or with a phenylalanine-restricted diet. Patients in the diet group may tend to consume carbohydrate-rich foods which have a risk for obesity. In this study, the prevalence of obesity+overweight among phenylketonuria patients either treated with phenylalanine-restricted diet or with $\mathrm{BH} 4$ were compared.Patients with phenylketonuria were divided into two groups on dietary treatment and $\mathrm{BH} 4$ treatment. Body mass index (BMI), BMI-percentile, and z-score values of patients were calculated and classified as underweight, normal-weight, overweight, and obese according to their nutritional status. The annual mean phenylalanine level of each patient is also evaluated. The study was done retrospectively.A total of 130 patients was included. 77 were receiving diet (female $(n, \%): 37,48.1 \%$; male $(n, \%): 40,51.9 \%$ ) and 53 were receiving $B H 4$ (female $(n, \%): 33,62.3 \%$; male $(n, \%): 20,37.7 \%)$ respectively. According to BMI-z-score, the sum of the ratio of obesity+overweight was found to be $35.1 \%$ in the diet group, $16.9 \%$ in the $\mathrm{BH} 4$ group. Ratio was significantly higher in diet group $(p=0.02)$. When obesity+overweight ratios were examined in terms of female/male distribution, no significant difference was found. Considering the correlation of obesity+overweight ratios with age in two groups, the median age of the patients with normal weight+underweight in the $\mathrm{BH} 4$ group were found as 46-months, and the median age of obese+overweight patients was 137-months $(p=0.001)$. For the same situation, there was no significant difference in the dietary treatment group $(p=0.92)$. Mean annual phenylalanine levels were significantly higher in obese+overweight patients $(p=0.047)$ in the BH4 treatment group but this difference was not significant in the diet group $(p=0.051)$.Patients on the phenylalanine-restricted diet have a risk of obesity or overweight. Therefore, attention should be paid not only to the phenylalanine levels of these patients but also to their weight control and dietary content.

Keywords: Phenylketonuria, diet, tetrahydrobiopterin, obesity, overweight

Correspondence: Banu Kadıoğlu Yılmaz, Erciyes University, Faculty of Medicine Department of Pediatric Nutrition and Metabolism, Kayseri, Turkey

E-mail: banukadioglu@yahoo.com.tr 


\section{Introduction}

Phenylketonuria $(\mathrm{PKU})$ is an inherited metabolic disorder that is caused by the deficiency of phenylalanine hydroxylase enzyme. ${ }^{1}$ Due to phenylalanine hydroxylase enzyme deficiency, conversion of phenylalanine (Phe) to tyrosine is affected completely or partially, and the accumulated phenylalanine in untreated cases causes irreversible brain damage. ${ }^{1}$ Phenylketonuria (PKU) is the most common inherited disorder of amino acid metabolism in Turkey. ${ }^{1,2}$ In the treatment of the disease, if patients are tetrahydrobiopterin $(\mathrm{BH} 4)$ responsive, $\mathrm{BH} 4$ treatment is started and if unresponsive, patients are treated with a phenylalanine restricted diet. ${ }^{3,4}$

Dietary treatment aims to keep the blood phenylalanine levels within the target values by applying a diet containing low phenylalanine which means low natural protein. ${ }^{5-7}$ Patients on dietary treatment tend to eat carbohydrate-rich foods and this situation creates a risk for obesity. ${ }^{5-7}$ Various studies are arguing that the prevalence of obesity in PKU patients are equal or increased to the general population of the related country. ${ }^{5-8}$

In this study, we aimed to compare the obesity ratios of our PKU patients receiving $\mathrm{BH} 4$ treatment and dietary treatment. We also compared the obesity ratios of our PKU patients with the overall obesity ratios in Turkish children.

\section{Material and Method}

Ethics committee approval was taken from local ethic committee (Decision No: 2021/470). All procedures were carried out in accordance with the ethical rules and the principles of the Declaration of Helsinki.

We included patients diagnosed with PKU, who were followed up at Erciyes University, Faculty of Medicine, Department of Pediatrics, Division of Pediatric Nutrition and Metabolism, and divided them into two groups according to their treatments, dietary treatment or $\mathrm{BH} 4$ treatment. Patients $<19$ years of age were collected. Our patients are from the city of Kayseri and the neighboring cities of Kayseri which reflects the population of, Central Anatolia Region, in Turkey. The PKU diagnosis was made by either measuring blood phe levels or both phe levels and genetic testing. $\mathrm{BH} 4$ responsiveness was defined as a $30 \%$ reductions of phe levels at the time of the $24^{\text {th }}$ hour after $20 \mathrm{mg} / \mathrm{kg} / \mathrm{dose}$ of $\mathrm{BH} 4$ administration. Patients receiving both $\mathrm{BH} 4$ and dietary treatment were excluded from the study. PKU patients without any treatment, with severe neurological problems, and patients who have additional diseases, were also excluded. Anthropometric measurements were done by using a Dens $i^{\circledR}$ branded digital weighing scale and stadiometer. Height of children under two years of age and those who are unable to stand stably enough were measured in the supine position on a measuring board. The weight and height of the patients were recorded routinely in their files in our clinic. The weight measurements were done with light clothes and the height measurements were done without shoes. Anthropometric calculations of the body mass index (BMI) $\left(\mathrm{kg} / \mathrm{m}^{2}\right)$, BMI percentile $(\%)$, and z-score values were evaluated retrospectively from the files of patients by using the age and gender-specific charts of the World Health Organisation (WHO) ${ }^{8}$

The overweight classification was as follows: for patients $<5$ years: BMl $z$ score $\geq 2$ and $<3$ SD, for patients $5-18$ years; $\mathrm{BMI} z$ score $\geq 1$ and $<2 \mathrm{SD}{ }^{8}$ Obesity classification was for patients $<5$ years: $B M I z$ score $\geq 3$ and for patients $5-18$ years: BMI $z$ score $\geq 2$ SD. ${ }^{8}$ Percentages of overweight+obesity and obesity were calculated respectively from BMI z scores and compared with the overall obesity prevalence of children in Turkey. Underweight status was defined as BMI $\mathrm{z}$ score $<-3$ SD. ${ }^{9}$ Annual mean phenylalanine levels were evaluated from the blood phenylalanine amino acid measurements $(\mathrm{mg} / \mathrm{dl})$ with the high-performance liquid chromatography (HPLC) analysis. The mean value of at least three measurements was calculated.

Statistical analysis was done with SPSS 15.0. Descriptive criteria are presented as mean, median, and percentage distribution. The compliance of the data to normal distribution was checked with the Kolmogorov-Smirnov test. To determine the mean differences between the groups, student t-test was used when parametric conditions were met, Mann Whitney $U$ test in cases where they could not be met, and Pearson Chi-square to compare the differences between percentages were used when necessary, and also Fisher's exact test was used. Pearson Correlation Analysis was used to evaluate the correlation. For the significance level, $p<0.05$ was taken.

\section{Results}

A total of 130 patients were included to the study. There were 77 patients (female $(n, \%): 37,48.1 \%$; male $(n, \%)$ : $40,51.9 \%$ ) receiving dietary treatment and 53 patients (female (n, \%): 33, 62.3\%; male (n,\%): $20,37.7 \%$ ) receiving $\mathrm{BH} 4$ treatment.

The distribution of nutritional status of the patients in the dietary treatment group and $\mathrm{BH} 4$ treatment group according to BMI z-score is given in table 1 below.

According to the BMI z-score, the ratio of obesity and overweight was found to be significantly higher in the dietary treatment group and it is shown in Figure 1 (dietary treatment group $35.1 \%, \mathrm{BH} 4$ treatment group $16.9 \%, \mathrm{p}: 0.02)$.

When obesity and overweight ratios were examined in terms of female / male distribution, no significant difference was found in both groups $(p=0.33$ in the group receiving dietary treatment and $p=0.49$ in the $\mathrm{BH} 4$ treatment group). 


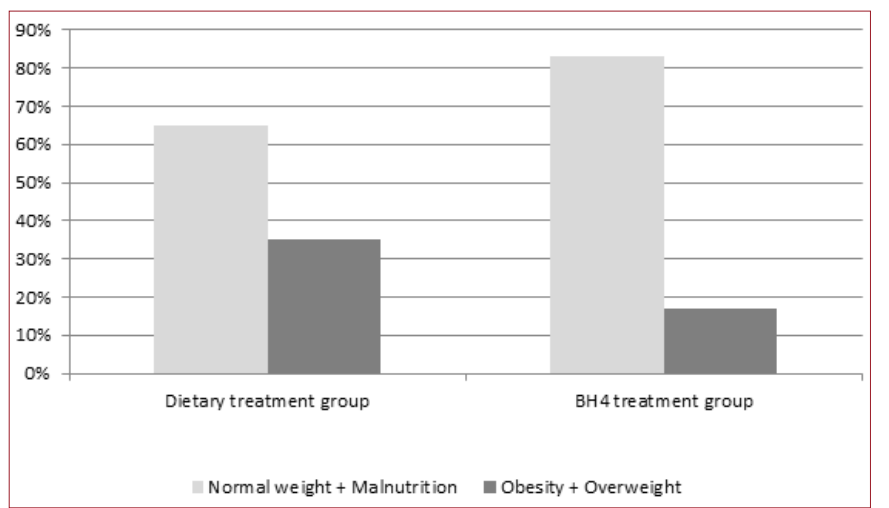

Figure 1. Percentage distribution of obesity + overweight status among the patient groups receiving dietary treatment and $\mathrm{BH} 4$ treatment

When the median age of the group receiving dietary treatment and the group receiving $\mathrm{BH} 4$ treatment was compared with the Mann-Whitney $U$ test, the median age of the group receiving $\mathrm{BH} 4$ drug was found to be significantly lower $(p=0.002)$ (Table 1$)$.

Table 1.

Number of patients, demographic features and analysis of nutritional status according to treatment groups

\begin{tabular}{|c|c|c|c|}
\hline & $\begin{array}{l}\text { Dietary } \\
\text { treatment } \\
\text { group }\end{array}$ & $\begin{array}{c}\text { BH4 } \\
\text { treatment } \\
\text { group }\end{array}$ & $\begin{array}{c}P \\
\text { value }\end{array}$ \\
\hline \multicolumn{4}{|l|}{ Gender } \\
\hline Male $(\mathrm{n}, \%)$ & $40(51.9)$ & $20(37.7)$ & \\
\hline Female (n,\%) & $37(48.1)$ & $33(62.3)$ & \\
\hline Total $(n)$ & 77 & 53 & \\
\hline Mean Age (month) & & & 0.002 \\
\hline Mean $\pm S S$ & $101.7 \pm 64.9$ & $66.1 \pm 49.2$ & \\
\hline Median (IQR) & $97(103)$ & $56(62)$ & \\
\hline \multicolumn{4}{|l|}{ Nutritional Status } \\
\hline Underweight $(n, \%)$ & $0(0)$ & $3(5.7)$ & \\
\hline Normal weight $(\mathrm{n}, \%)$ & $50(64.9)$ & $41(77.4)$ & \\
\hline Overweight (n,\%) & $15(19.5)$ & $7(13.2)$ & \\
\hline Obesity $(n, \%)$ & $12(15.6)$ & $2(3.8)$ & \\
\hline Nutritional Status Subgroups & & & 0.02 \\
\hline Underweight+normal weight (n,\%) & $50(64.9)$ & $44(83.1)$ & \\
\hline Overweight+obesity $(n, \%)$ & $27(35.1)$ & $9(16.9)$ & \\
\hline
\end{tabular}

When the correlation between age (in months) and BMI $\mathrm{z}$-score was examined in the $\mathrm{BH} 4$ treatment group, it was found that they were positively correlated with a low degree and this correlation was statistically significant (R: 0.33 and $p: 0.017$ ).

In the $\mathrm{BH} 4$ treatment group, the median age of the patients in the normal weight+underweight subgroup were found 46 months, and in the overweight+obesity subgroup 137 months $(p=0.001)$. In the dietary treatment group, the median age of the patients in the normal weight+underweight subgroup were found at 96 months, and in the overweight+obesity subgroup at 99 months $(p=0.92)$ (Table 2).

When the median annual phe level of the patients in the dietary treatment group and $\mathrm{BH} 4$ treatment group were compared, the mean annual phe level of the group that received the diet was found to be higher; $9,6 \mathrm{mg} / \mathrm{dl}$ and $4,5 \mathrm{mg} / \mathrm{dl}$, respectively $(\mathrm{p}<0.001)$.
Table 2.

Comparison of the median age of normal weight+underweight and obese+overweight children in treatment groups

\begin{tabular}{|c|c|c|c|}
\hline Groups & $\begin{array}{l}\text { Normal weight+ } \\
\text { Underweight } \\
\text { Mean士SS Median } \\
\text { (IQR) }\end{array}$ & $\begin{array}{l}\text { Overweight+ } \\
\text { Obesity } \\
\text { Mean } \pm S S \\
\text { Median (IQR) }\end{array}$ & $p$ value \\
\hline $\begin{array}{l}\text { BH4 treatment } \\
\text { group, mean age } \\
\text { (month) }\end{array}$ & $\begin{array}{c}51.2 \pm 34.6 \\
46(45)\end{array}$ & $\begin{array}{c}138.7 \pm 46.4 \\
137(84)\end{array}$ & 0.001 \\
\hline $\begin{array}{l}\text { Dietary treatment } \\
\text { group, mean age } \\
\text { (month) }\end{array}$ & $\begin{array}{c}100.8 \pm 67.7 \\
96(112)\end{array}$ & $\begin{array}{c}103.4 \pm 60.4 \\
99(77)\end{array}$ & 0.92 \\
\hline
\end{tabular}

Considering the annual median phe levels in normalweight patients and obese+overweight patients in the dietary treatment group, the annual median phe levels in obese+overweight patients were higher, but the difference was not statistically significant $(p=0.051)$.

\section{Discussion}

Obesity ratios vary within the countries. According to 2011-2012 National Health and Nutrition Examination Survey (NHANES) data in the United States of America, the prevalence of overweight in children and adolescents was reported as $31.8 \%$ and obesity prevalence as $16.9 \%$ (obesity+overweight $48.7 \%$ ). ${ }^{10}$

In Turkey, these ratios are lower. The prevalence of overweight is $14.3 \%$ and obesity is $6.5 \%$ (overweight+obesity, 20.8\%). ${ }^{11}$ This may because fastfood consumption is less in Turkey and homemade food is widespread. Another reason for this may be the socioeconomic status of the families in Turkey is worse and there may be restrictions in consuming fast-food.

Studies in the literature, the prevalence of obesity and overweight in patients with PKU on dietary treatment was compared with the obesity prevalence of the related country or within the healthy control group. ${ }^{6-8}$ In this study, obesity and overweight ratios of patients with PKU on dietary treatment were compared with patients with again $\mathrm{PKU}$ patients on $\mathrm{BH} 4$ drug treatment. The fact that both of the groups had PKU, showed the positive side of the study, while the median ages of the $\mathrm{BH} 4$ treatment group in the study were significantly younger than the dietary treatment group (diet group median age 97 months, $\mathrm{BH} 4$ group median age 56 months, $p=0.002$ ) constitutes the limitation of the study. $\mathrm{BH} 4$ treatment is approved for adults and pediatric patients of 4 years of age and over in 2008. ${ }^{12}$ $\mathrm{BH} 4$ treatment under age 4 is approved in Turkey in 2015 and this situation causes the $\mathrm{BH} 4$ treatment group to be younger than the dietary treatment group. ${ }^{12}$

In this study, the ratio of obesity+overweight in the dietary treatment group was found to be statistically higher $35.1 \%$ and the $\mathrm{BH} 4$ treatment group was $16.1 \%$ $(p=0.02)$. The obesity+overweight prevalence in PKU patients on the dietary treatment group was also higher than the overall obesity prevalence in Turkish children (obesity+overweight ratio of the dietary treatment group was $35.1 \%$ and overall obesity+overweight 
ratio of Turkish children was $20.8 \%) \cdot{ }^{11}$ Because of a restricted natural protein diet, PKU patients tend to consume carbohydrate rich foods and this may cause excess caloric intake and obesity. In the $\mathrm{BH} 4$ treatment group, which they have no diet, the obesity+overweight ratio is lower than the dietary treatment group and also lower than the overall obesity prevalence of Turkish children.

Studies from the USA and European countries, it was emphasized that the obesity prevalence was higher in girls in patients with PKU on dietary treatment, whereas in our study, the ratio of obesity+overweight was higher in boys (female $27 \%$; male $42.5 \% p=0.33$ ) but this was not statistically significant. ${ }^{7,8}$ Considering the overall ratio of childhood obesity in Turkey, the ratio is higher in the male gender which is overweight+obesity ratio in male gender $22.6 \%$ and $18.9 \%$ in the female gender. ${ }^{11}$

In another multicenter study which is also including Turkey, 8 centers participated in the study with 397 patients. ${ }^{8}$ Gokmen Ozel et al. ${ }^{8}$ from the Ankara group gave the obesity+overweight ratio lower than our study $19.8 \%, 35.1 \%$ respectively. In the same study, the ratio of obesity was found to be higher in girls, contrary to our study ( $21.3 \%$ girls; $18.7 \%$ boys). ${ }^{8}$ The study of the Ankara group was done in 2014 but our study was done in 2019. Obesity and the overweight problem is increasing problem over the years. The 5 -year difference between the two studies may have caused this difference. Ankara group was the first group that initiates neonatal screening program for phenylketonuria. Their patients are from Ankara and also from the Eastern Anatolia region which socioeconomic status is below the average of Turkey. Nutrition patterns vary from country to country, as well as from region to region within the same country. This may explain the different ratios of obesity among studies conducted in different regions. Kayseri and its surrounding provinces have a diet rich, especially in pastry foods. This situation may have been effective in the high rates of obesity in our study.

In addition, in our patient group, it was observed that the phe levels of the dietary treatment group were higher than the BH4 treatment group $(9,6 \mathrm{mg} / \mathrm{dl}$ and $4,5 \mathrm{mg} / \mathrm{dl}$, respectively $(p<0.001))$. The reason for this may be that the $\mathrm{BH} 4$ treatment group does not require any dietary treatment. The dietary treatment group has a strict protein-restricted diet and many patients have difficulties in strict compliance with this diet. They can not fully comply with the diet so their phe levels are higher than the $\mathrm{BH} 4$ treatment group.

In another study from Portugal, it was found that the ratios of obesity or overweight and the risk of developing metabolic syndrome were higher in the PKU dietary treatment group when compared with the control group but the difference was not statistically significant. ${ }^{5}$ There are different results from different countries. This situation may be explained by the fact that different countries have different nutrition styles.

In this study when the relationship between the obese or overweight patients and age was examined, a significant correlation was not found in the dietary treatment group, but a statistically significant correlation was found in the $\mathrm{BH} 4$ treatment group in the direction of increasing obesity with increasing age (median age of the normal weight group was 46 months, the median age of the obese/overweight group was 137 months, $p=0.001)$. This situation raises the question of whether if the age of the $\mathrm{BH} 4$ treatment group was equal to the age of the dietary treatment group, would there be no statistical difference between obesity rates? However, to reveal this, it is necessary to follow the obesity rates of the same $\mathrm{BH} 4$ group in the following years prospectively. It is also important to do more studies that are comparing both the $\mathrm{BH} 4$ treatment group and dietary treatment group to see the differences. We also have not much information on how the phenylalanine restricted diet affects the PKU patients in a long-term period.

\section{Conclusion}

Obesity and overweight risk of PKU patients on the dietary group are higher than society and also higher than PKU patients who were not on diet. Therefore, attention should be paid not only to the phenylalanine levels of these patients but also to their weight control and dietary content. In the early period, if necessary, calorie restriction should be applied in their diets, or alternative solutions should be produced to increase the compliance of patients who do not comply with the diet. It is necessary to prevent the perception in the patients and also the parents that the phenylalanine restriction in diet is to be seen as the main aim in dietary treatment. It is also important to mention that phenylalanine-free high-calorie foods may not be consumed limitless in patients.

Acknowledgements: This study was accepted as an oral poster the 6th Anniversary Meeting of the EPA, February 27-29 2019, Kayseri

Author Contributions: All of the authors declare that they have all participated in the design, execution, and analysis of the paper and that they have approved the final version

Conflict of Interest: All the authors declare that they have not received any financial support or other benefits from commercial sources for the work described in this paper. They also declare that they have no other financial interests that could create a potential conflict of interest or the appearance of a conflict of interest with about this work.

Ethics Committee Approval: Ethics committee approval was taken from local ethic committee (Decision No: 2021/470).

Financial Disclosure: The authors declared that this study has received no financial support.

Informed Consent: The patient consent form could not be obtained because the study was retrospective and informations were obtained from the medical records of the patients. 


\section{References}

1. Blau N, van Spronsen FJ, Levy HL. Phenylketonuria. Lancet. 2010;376:1417-1427. [CrossRef]

2. Ozalp I, Coşkun T, Tokatli A, et al. Newborn PKU screening in Turkey: at present and organization for future. Turk $J$ Pediatr. 2001;43:97-101. [CrossRef]

3. Fiege B, Blau N. Assessment of tetrahydrobiopterin (BH4) responsiveness in phenylketonuria. J Pediatr. 2007;150:627-630. [CrossRef]

4. van Wegberg AMJ, MacDonald A, Ahring K, et al. The complete European guidelines on phenylketonuria: diagnosis and treatment. Orphanet J Rare Dis. 2017;12:162. [CrossRef]

5. Rocha JC, van Spronsen FJ, Almeida MF, et al. Dietary treatment in phenylketonuria does not lead to increased risk of obesity or metabolic syndrome. Mol Genet Metab. 2012;107:659-663. [CrossRef]

6. Robertson LV, McStravick N, Ripley S, et al. Body mass index in adult patients with diet-treated phenylketonuria. J Hum Nutr Diet. 2013;26:1-6. [CrossRef]
7. Burrage LC, McConnell J, Haesler R, et al. High prevalence of overweight and obesity in females with phenylketonuria. Mol Genet Metab. 2012;107:43-48. [CrossRef]

8. Gokmen Ozel H, Ahring K, Bélanger-Quintana A, et al. Overweight and obesity in PKU: The results from 8 centres in Europe and Turkey. Mol Genet Metab Rep. 2014;1:483-486. [CrossRef]

9. World Health Organization, Body mass index (BMI), http://www. euro.who.int/nutrition/20030507_1 (accessed December 2009)

10. Liu $X$, Chen $Y$, Boucher NL, et al. Prevalence and change of central obesity among US Asian adults: NHANES 2011-2014. BMC Public Health. 2017;17:678. [CrossRef]

11. Pekcan G, Karaağaoğlu N, Samur G. Türkiye'de okul çağ çocuklarında (6-10 yaş grubu) büyümenin izlenmesi (TOÇBí) projesi araştırma raporu, Ankara, 2011. (In Turkish) [CrossRef]

12. Ünal Ö, Gökmen-Özel H, Coşkun T, et al. Sapropterin dihydrochloride treatment in Turkish hyperphenylalaninemic patients under age four. Turk J Pediatr. 2015;57:213-218. [CrossRef] 